\title{
ASPECTOS JURÍDICOS DO TRANSEXUALISMO
}

\author{
Aracy Augusta Leme Klabin \\ Professora aposentada do Departamento de Direito Civil da \\ Faculdade de Direito da Universidade de São Paulo
}

Resumo:

A maior parte desta pesquisa para a elaboração da tese em questão fundou-se em leis, jurisprudência e trabalhos esparsos de doutores em Medicina Legal; juízes e peritos americanos em psicologia, psiquiatria, urologia e endocrinologia. Eles estão unânimes em enfatizar a complexidade da matéria, tendo em vista o insuficiente conhecimento dela e a inexistência de soluções adequadas. Numa sociedade, na qual vivemos e onde todos clamam por direitos e desrespeitam o direito do outro, onde a irresponsabilidade é a regra, onde a procura da satisfação pessoal, do prazer imediato e a celebração do "ego" "sex" é a palavra de ordem. Oh! Deus! Que "pesueria intellectus!"

Confrontando-se com toda a espécie de problemas sociais, a sociedade é continuamente desafiada a apresentar soluções para problemas emergentes e estabelecer seus limites. De fato, a sociedade através de seus órgãos judiciais está sendo convocada a apresentar solução ao problema dos transexuais. Esta sociedade egocêntrica aderente ao princípio da absoluta liberdade, está agindo, em alguns países, como os pais que para resistir aos contínuos pedidos e desejos de seus filhos, fazem concessões desarrazoadas com o úniço propósito de escapar às outras pressões. Assim, fazem concessões a este grupo "aborrecedor" sob forma de lei, a qual lhes permitirá mudar o nome e o sexo nos Registros Públicos; fecham os olhos à cirurgia e como conseqüência criam um exército de eunucos, cujos problemas moral e mental continuam sem solução. É nossa opinião que os indivíduos sob exame sofrem de desordem mental e de personalidade, o que os colocam em uma área limítrofe entre a neurose e a psicose. Os psicanalistas reconhecem sua incapacidade para curar tais desordens e não reconhecem que esses indivíduos sejam vítimas de doenças mentais. Mas, pode-se argüir, qual é a extensão de tal conhecimento psicológico? Não poderia ser deficiente? É nossa opinião que deve ser dado a esses indivíduos todo o tratamento médico possível, contudo não deve ser dada autorização para a cirurgia de alteração, a qual seria o ponto fatal de não-retorno.

Portanto, deveria ser promulgada lei, considerando como crime qualquer ato de mutilação praticado pelo próprio indivíduo ou por terceiros o médico , os quais deverão ser devidamente processados. Ademais, proibidas alterações nos Registros Públicos.

\section{Abstract:}

The greater part of the research for the elaboration of this thesis found its sources in the laws, jurisprudence, authorities and scattered studies 
of forensic doctors, judges and United States experts in psychology, psychiatry, urology and endocrinology.

They are all unanimous in emphasizing the complexity of the matter in view of the insufficient knowledge to face it, the repetition of the cases and the almost inexistence of adequate solutions therefor.

In a society such as the one in which we presently live, where everybody claims for his rights, rather than claiming for the respect for the rights of others, where the irresponsibility is the governing rule, where the escape to the purely personal pleasures is a common place, which has no perspectives for the future and thus, is not concerned with anything that exceeds its immediate needs, men turn to the only thing that really matters, which is their mental development, in the belief that the mental health means the destruction of "inhibitions" and the never ending celebration of the "ego" They attribute to sex values that are not inherent thereto and all claim now for solutions to their problems which, in this incessant pendular movement, become confusing and certainty thereon.

But, while facing this present social disorders, the society is imperatively called upon to present solutions to the emergent problems and to establish their limits.

In fact, the society, through its judicial organs, is called upon to present a solution for the problems of the transsexuals.

This egocentric society, adherent to the principle of absolute freedom, is in some countries acting like some parents who, in order to obviate their children's continuous demands an'd wishes, make unreasonable concessions with the sole purpose of escaping from further pressure put upon them. Thus, there are granted to an "annoying" group some concessions under the form of law which allow them to change their name and sex in the Public Records, close the eyes for the reassignment surgery and, as a consequence, create an army of eunuchs, whose mental and moral problems continue unresolved.

Because the individuals under examination, in our opinion, suffer from mental and personality disorders which are in the border line between the neurosis and the psychosis. The psychoanalysts acknowledge their inability to cure such disorders and do not consider such individuals as victims of mental illnesses. But, it may be argued, what is the extension of such psychological knowledge? Couldn't it be deficient?

It is our opinion that every possible medical treatment should be made available to such individuals, but without ever accepting the reassignment surgery, which would be the fatal point of no return. Therefore, laws should be enacted, defining as a crime any act of mutilation, practiced either by the individual himself or by a third party - the doctor -, both of them being liable therefore. And, furthermore, prohibiting the alterations of Public Records. 
Sumário:

Prefácio-Razões

I - O problema do transexual

1. Caracterização do sexo

2. Os transexuais

II Histórico

III - A cirurgia de conversão como tentativa de solução do problema dos transexuais

1. Preliminares médico-legais e éticas

2. Conseqüências

IV - Direito Comparado

1. A solução do problema na esfera civil

a. Considerações sobre o casamento de transexuais

b. Fundamentos para o divórcio de transexuais

c. Dificuldades para contrair matrimônio

d. Relacionamento entre pais transexuais e filhos

e. Direitos da mulher e filhos do castrado na Dinamarca

f. Herança

g. Identidade legal e registro civil

h. Decisões prolatadas por tribunais alemão e suíço

i. Casos de alteração de sexo - decisões prolatadas por juízes e tribunais brasileiros

j. Outros registros ou documentos

V - O Direito Social

1. Pagamento de auxílios médicos e sociais

2. Discriminação no trabalho

VI O Direito Público

1. A Lei Penal

2. A Lei Magna

VII - Conclusões

Bibliografia 
Prefácio Razões

Duas foram, essencialmente, as razões que nos levaram a escolher Aspectos Jurídicos do Transexualismo como tema deste trabalho: sua atualidade e a falta de disposições legais que regulam as pretensões dos transexuais (antes e depois da cirurgia de conversão).

Não há dúvida quanto à atualidade da matéria. Este trabalho foi efetuado para dar uma breve avaliação sobre o transexualismo à luz do conhecimento atual. Particular consideração foi dada às causas, sintomas, implicações culturais e legais e ao papel desempenhado pelo cirurgião na terapia dessa entidade.

Processos judiciais foram e estão sendo instaurados em vários países do mundo.

No Brasil, encontra-se em curso, ainda sem solução, processo criminal contra médico, autor de cirurgia de conversão. Desse, e de outros processos, trataremos mais adiante, pormenorizadamente.

Por outro lado, a falta de dispositivos legais suscita a perplexidade e a curiosidade em torno do assunto, que aguarda soluções que precisarão ser encontradas, estudadas e aplicadas, como demonstraremos ao longo deste trabalho. Consideramos o problema, pois, de enorme interesse para o Direito, talvez não tanto pela sua ocorrência, que não é tão freqüente, quanto pelo seu conteúdo humano.

\section{O Problema do Transexual}

\section{Caracterização do sexo}

No estudo e desenvolvimento do tema, uma primeira indagação que se põe é a relativa à definição do sexo.

Pode-se, desde logo, afirmar que não existe uma definição jurídica de sexo. Ponto de relevante importância é o fato de que os códigos legais jamais se detiveram em demonstrar a diferença entre homem e mulher. A constatação sobre o sexo da criança, ao nascer, é feita pelo médico ou parteira, ou ainda por qualquer pessoa que auxilie a parturiente, com base num exame superficial da genitália externa da criança; será o sexo assim determinado o que constará do registro de 
nascimento. Este sexo será o masculino ou o feminino, que é a classificação fundamental encontrada em todos os sistemas legais conhecidos.

Recentemente, porém, começou a ciência médica a verificar que, em muitos casos, essa classificação não é satisfatória, pois determinados indivíduos não se enquadram perfeitamente nem num sexo, nem no outro. Embora seja praticamente impossível ou, em outras palavras, altamente improvável que a tradicional divisão dos indivíduos em dois sexos seja abandonada, pode-se dizer, por outro lado, que, tendo em vista as importantes implicações legais e sociais na determinação do sexo, deve essa determinação ser feita com base não apenas nas aparências.

Ao contrário, análise cuidadosa deve ser feita dos parâmetros da sexualidade humana. $\mathrm{O}$ objetivo de tal análise será o encontro de um padrão pelo qual se identifique o verdadeiro sexo do indivíduo, preservando, embora, a tradicional dicotomia sexual.

Os seguintes elementos são considerados relevantes pela Medicina:

a) Constituição cromossômica sexual;

b) Sexo gonadal;

c) Padrão do sexo hormonal;

d) Órgãos sexuais internos: útero ou vas deferens;

e) Genitália externa;

f) Características secundárias do sexo;

g) Sexo de criação (geralmente o sexo fixado no nascimento);

h) Sexo assumido ou sexo psicológico. ${ }^{1}$

Assim, para o Instituto Médico Legal de São Paulo, o sexo é diagnosticado sob o aspecto pluridimensional, isto é, há um sexo genético, um cromatínico, um endócrino, um gonádico, um morfológico, um psíquico e, finalmente, um jurídico.

Qualquer um desses critérios poderia ser utilizado na determinação do sexo da média das pessoas. Qualquer critério, por outro lado, tomado isoladamente, pode falhar com determinados indivíduos. 

de Klinefelter. ${ }^{2}$

O teste cromossômico é falho se aplicado aos portadores de Síndrome

O padrão gonadal, isoladamente, é inadequado perante o verdadeiro hermafrodita, que possui as gônadas de ambos os sexos. Aqui encontramos uma vexata quaestio, ou seja, existe ou não o hermafrodita verdadeiro?

Para certos autores, como Flamínio Fávero, ${ }^{3}$ Almeida $\mathrm{Jr}^{4}{ }^{4}$ e Klebs, para mencionar apenas alguns, não existe o hermafroditismo verdadeiro, existindo apenas o pseudo-hermafroditismo. No entanto, para Claus Overzier, ${ }^{5}$ existe o hermafroditismo verdadeiro, dando-nos ele conhecimento autêntico de 146 casos, desde o ano de 1900. Concluindo, estes casos ocorreram na Alemanha, pois esse autor é professor de Medicina Interna na Universidade de Mainz.

O equilíbrio do hormônio sexual não é indicador seguro do sexo, pois pode variar em razão da administração de drogas e pode ser drasticamente afetado pela castração, com mudanças gradativas nas características sexuais secundárias.

O padrão genial é igualmente inadequado, tomado isoladamente, pois anormalidades nos órgãos genitais são relativamente freqüentes.

O sexo de criação, geralmente determinado pelo sexo fixado no nascimento, fundado no exame da genitália, é relevante na determinação do sexo do hermafrodita, pois a ambigüidade sexual deste pode ser resolvida pelo desenvolvimento e ajustamento sexual em determinado sexo. Falha completamente, todavia, com referência aos transexuais.

Do sexo psicológico é dito, pela Medicina, que deveria ter relevante importância na fixação do sexo do indivíduo. ${ }^{6}$

2. Síndrome de Klinefelter compreende os indivíduos fenotipicamente masculinos, cromatinopositivos, nos quais se encontra sempre elevada taxa de gonadotropinas. Com frequência mostram discreta ou completa debilidade mental, mostrando quase sempre micro ou macroginecomastia permanente ou temporária. Apresentam 47 cromossomos em vez de 46 , sendo geneticamente XXY, podendo ainda apresentar a forma XXXY, etc. Heller e Nelson falam ainda de três tipos de pacientes na Síndrome de Klinefelter: pacientes de aspecto normal, eunucóides e moderadamente eunucóides. Estes autores consideram como sintomas obrigatórios para se diagnosticar a síndrome: testículos pequenos, azoospernia e elevada taxa de gonadotropinas.

Sadi, Afiz - Urologia, notas bibliográficas, 1975.

3. Fávero, Flamínio, Medicina Legal, v. 2, Livraria Martins.

4. Almeida Jr., Medicina Legal, p. 267, $6^{8}$ ed., Cia. Nacional.

5. Overzier, Claus, La Intersexualid, Editorial Científico-Médica, Madrid, 1963.

6. Transsexualism, Cornell Law Review, v. 56:963, 1971.

Transsexualism, Medico Legal Journal, 36:174, 1968. 
Procuramos dar acima uma idéia, embora pálida, da complexidade da questão referente à determinação do sexo do indivíduo que, parece-nos, não vem sendo tratada com o cuidado que seria de se esperar em virtude dessa mesma complexidade. ${ }^{7}$ Ao contrário, a determinação do sexo, repita-se, continua a ser feita através de exame superficial dos órgãos genitais externos, exclusivamente.

2. - Os transexuais

Os primeiros registros impressos do comportamento humano indicam que o transexualismo existiu bem antes de ter recebido uma denominação. Mas, até que a Medicina moderna reconhecesse, definisse e desenvolvesse terapias para essa entidade, o transexual enfrentou sozinho suas dificuldades por meios nãosatisfatórios e freqüentemente trágicos. ${ }^{8}$

Foi o médico americano, dr. H. Benjamin, o pioneiro no uso da palavra transexual, e, também, no tratamento desses indivíduos, considerando-os como "hermafrodita-psíquico". 9

O transexual é um indivíduo anatomicamente de um sexo, que acredita firmemente pertencer ao outro sexo. Esta crença é tão forte que o faz obcecado pelo desejo de ter o corpo alterado, a fim de ajustar-se ao "verdadeiro" sexo, isto é, ao seu sexo psicológico.

A Associação Paulista de Medicina nos dá a seguinte conceituação: "transexual é o indivíduo com identificação psicossexual oposta aos seus órgãos genitais externos com o desejo compulsivo de mudança dos mesmos" 10

O transexualismo tem sido chamado de "cisão entre o sexo morfológico e psicológico", "uma personalidade feminina em um corpo masculino" anima mulieris in corpore virile inclusa."

7. Paiva, Luiz Miller de, Medicina Psicossomática, p. 69, 1966.

Tovel, Harold M. M., Clinicas Obstétricas y Ginecológicas, Nueva Editorial Interamericana, 1973.

Revista de Terapêutica Médica, "Ars Curandi”, n. 2, p. 26, abril de 1968.

8. Guidelines for Transsexuals, Erickson Education Foundation Publication.

9. Benjamin, H., The Transsexual Phenomenon, New York: The Julian Press, 1966.

10. O Médico Paulista, jornal da Ass. Paulista de Medicina, n. 169, ano X.

11. Ética Médica e Lei Penal, artigo publicado em O Estado de S. Paulo, 12 de março de 1976. Solomon, Philip e Patch, Vernon D., Handbook of Phychiatry, Lang Medical Publications, 1969. 
A maior parte dos especialistas em identidade sexual concorda que a condição de transexual se estabelece antes da criança ter capacidade de discernimento, provavelmente nos primeiros dois anos de vida, afirmando alguns que isso pode ocorrer até mais cedo, antes do nascimento, durante o período fetal. ${ }^{12}$

A sua evolução se processaria em três fases distintas:

$\left.l^{\circ}\right)$ transexualismo psicógeno, quando se instala tendência de pertencer ao sexo oposto, associada ao narcisismo;

$2^{\circ}$ ) fase ligada à ação terapêutica hormonal, efetivada pelos próprios pacientes, na qual surgem sinais de feminilização como ginecomastia e distribuição de pelos do tipo feminino;

$3^{\circ}$ ) estado onde se processa tipicamente "profunda e total conviç̧ão de pertencer ao sexo oposto, a plena e definitiva configuração da síndrome clínica, que confere ao transexual os caracteres precisos da perversão sexual" ${ }^{13}$

O transexual (95\% dos pacientes são masculinos) tem, repita-se, um intenso e obsessivo desejo de completa transformação sexual: física, mental, legal e social. Tem a impressão de ser, na realidade, uma mulher que a natureza, por um erro cruel, humilhou e gravou com a genitália masculina. ${ }^{14}$

Como resultado dessa atitude, os órgãos sexuais visíveis são objeto de nojo, ofensa e desgosto e são considerados uma deformação (anátema).

Existem inúmeras teorias que procuram explicar a origem do transexualismo; entre elas: a teoria da origem divina, a teoria traumática, a teoria genética e endócrina, a teoria cerebral, a teoria psicológica e a teoria psicanalítica. ${ }^{15}$

Cada uma dessas teorias procura explicar, de acordo os estudos ou pesquisas de seus autores, qual seria a causa fundamental do transexualismo, até hoje não-determinada.

O dr. Robert T. Rubin, professor de Psiquiatria da Faculdade de Medicina da Universidade da Califórnia, Los Angeles, considera o transexualismo como uma anomalia, como uma forma específica de doença psíquica. ${ }^{16}$

12. Legal Aspects of Transsexualism, Erickson Education Foundation Publication.

13. Rodrigues, Armando Canger, Aspectos Éticos do Transexualismo, trabalho apresentado no XI Congresso Brasileiro de Cirurgia Plástica, Belo Horizonte, 1974.

14. Benjamin, H. e Ihlenfeld, Charles L., The Nature and Treatment of Transsexualism, Reprint Medical Opinion of Review, v. 6, n. 11, november, 1970.

15. Block, Norman L. e Tessler, Arthur N., Transsexualism and Surgical Procedures, Reprint Medical Aspects of Human Sexuality, february, 1973. 
O dr. John Money, professor de Psicologia Médica da Faculdade de Medicina Johns Hopkins Univesity, afirma que o transexualismo é uma desordem ou disforia de identidade de sexo que ocorre em uma pequena parcela da população, em todos os países do mundo. Concorda que "a etiologia da condição permanece totalmente desconhecida. Entretanto, acredita-se que possa ser causada, em parte, por mau funcionamento de hormônios antes do parto. A psicoterapia, no caso, não é eficiente e nem o tratamento com drogas" 17

Por sua vez, Jan Walinder, professor-assistente de Psiquiatria da Universidade de Gotemburgo, Suécia, também insiste em que, se o paciente tiver atingido a idade de pós-puberdade, a entidade não responde a psicoterapia ou a qualquer outra medida. ${ }^{18}$

O Instituto Médico Legal de São Paulo confirma esses entendimentos: ${ }^{19}$ "o estudo da literatura médico-legal a respeito do transexualismo mostra que os individuos que apresentam essa entidade são doentes que sofrem de distúrbios psíquicos, geralmente graves desajustamentos, angústia, que podem chegar até ao desespero, sendo levados à auto-emasculação e ao suicídio. Nestes termos parece não haver dúvidas de que esses doentes necessitam do esteio da Medicina. Ocorre que a experiência já grande, levada a efeito em diversos países, mostra que o tratamento pela psicoterapia-psicanalítica ou pela psiquiatria revelase inútil, sem resultado benéfico, em nada modificando o estado mental do transexual adulto"

$\mathrm{O}$ dr. Benjamin e o dr. Ihlenfeld asseveram que esses pacientes não demostram áreas de psicose, mas revelam intensa obsessão pela redeterminação sexual, daí ser o tratamento psicanalítico ineficaz. ${ }^{20}$

Assim, o tratamento psicoterápico desses indivíduos tem sido um total malogro, dizendo-se, portanto, que o transexual somente vive para o dia em que seus órgãos sexuais odiados sejam removidos. ${ }^{21}$

16. Idem, n. 14.

17. Afirmaçðes feitas em cartas juntadas ao processo criminal n. 20/76 da $17^{\mathrm{a}}$ Vara Criminal.

18. Idem.

19. Instituto Médico Legal de São Paulo, laudo de exame de corpo de delito juntado ao processo criminal n. 20/76, $17^{\mathrm{a}}$ Vara Criminal de São Paulo.

20. Benjamin, H., The Transsexual Phenomenon, New York: The Julian Press, 1966.

21. Meyers, David William, Problem of Sex Determination and Alteration, in Médico-Legal Journal, v. 36, p. 174, 1968. 
Distinções

Antes de tratarmos da cirurgia, convém que façamos a distinção entre o transexualismo, transvestismo, homossexualismo, fetichismo e hermafroditismo.

a) Transexualismo é a entidade caracterizada por indivíduo biologicamente normal que insiste em transformar, cirúrgica e hormonalmente, 0 sexo. $\mathrm{O}$ transexualismo se subdivide em primário e secundário.

$\mathrm{O}$ primário compreende aqueles pacientes cujo problema de transformação do sexo é precoce, impulsivo, insistente e imperativo, sem ter desvio significativo, tanto para o transvestismo quanto para o homossexualismo. É chamado, também, de esquizossexualismo ou metamorfose sexual paranóica.

O secundário (homossexuais transexuais) compreende aqueles pacientes que gravitam pelo transexualismo somente para manter períodos de atividades homossexuais ou de transvestismo (são primeiramente homossexuais ou travestis).

O impulso transexual é flutuante e temporário, motivo pelo qual podemos dividir o transexualismo secundário em transexualismo do homossexual e do travesti. Por isso a mulher transexual deve ser classificada como forma secundária (homossexual) de transexualismo. ${ }^{22}$

b) Transvestismo ou eonismo é a entidade na qual os indivíduos apresentam, como característica principal, o uso da roupagem cruzada, por fetichismo ou por defesa.

O transvestismo pode se traduzir de varias formas, assim:

transvestismo não-masoquista - atividade sexual sem medo ou

angústia;

transvestismo sadomasoquista - atividade sexual sadomasoquista (durante a relação, ou masturbação, o indivíduo submete-se ao açoite, escravidão e sofrimento físico, em fantasia ou na realidade);

U. S. Supreme Court Proceedings, em The Family Law Reporter, v. 1, n. 17, march 11, 1975.

Money, J., e Green, R., Transexualism and Sex Reassignment, Johns Hopkins University Press, Baltimore, 1968.

Block, Norman L., e Tessler, Arthur N., Transsexualism and Surgical Procedures, Reprint Medical Aspects of Human Sexuality, february, 1973.

22. Rodrigues, Armando Canger, Transexualismo, Transvestismo, Homossexualismo $e$ Fetichismo. Trabalho apresentado no X Congresso Brasileiro de Medicina Legal, São Paulo, 08.12.1974. 
- transvestismo fetichista o fetiche produz excitação sexual;

transvestismo não-fetichista o fetiche não produz excitação sexual, serve para aliviar a ansiedade acerca da identidade sexual e favorecer a segurança.

c) Homossexualismo: caracteriza-se por indivíduos que têm preferência evidente para a relação sexual com pessoas do mesmo sexo.

Divide-se em várias formas:

homossexualismo ativo - refere-se ao paciente que faz o papel ativo; neste caso, predomina o desejo de vingança ou sadismo;

homossexualismo passivo o paciente identifica-se com a mãe (é a figura do ego combinado, isto é, fantasia de possuir os dois sexos em si);

homossexualismo por trauma na fase anal e fixação materna;

homossexualismo por excessiva fixação à mãe (complexo de Édipo);

homossexualismo por falta de identificação com o pai;

homossexualismo ocasional é o caso dos psicóticos tipo esquizofrênico, toxicômano e por circunstâncias especiais (vida em penitenciária, marítima, etc.);

- homossexualismo inconsciente - o paciente não tomou conhecimento de suas manifestações homossexuais manifestadas pelo donjuanismo, atitude de ciúme, paranóia, etc.

d) Fetichismo: nesta entidade, os indivíduos apresentam desejos sexuais que surgem principalmente à vista ou toque de determinados objetos ou de certas partes do corpo que não as sexuais, sendo os objetos, geralmente, símbolos da pessoa amada.

Assim, o fetiche pode ser:

objeto (roupa íntima, fotografia, imagens, etc.);

- partes do corpo humano e animal.

Como já foi explanado, esses conceitos não são sinônimos. Embora se possa dizer que todo transexual é travesti, poucos dos travestis são transexuais. O travesti não deseja, ao contrário do transexual, a cirurgia de conversão, pois seus órgãos sexuais são fontes de satisfação e não de desgosto ou repulsa. O travesti, também ao contrário do transexual, reconhece-se como homem ou mulher, de acordo com seus órgãos sexuais e as característica sexuais secundárias. ${ }^{23}$ 
"Fenomenologicamente, a inversão da identidade psicossexual constitui o problema nuclear dos transexuais, que podem assumir o transvestismo, não por fetichismo com objetivo social, mas como meio de reduzir a tensão $e$ ansiedade geradas pelo antagonismo sexual entre o corpo e a mente. 24

Também não se confunde o transexual com o homossexual. $O$ transexualismo, como entidade clínica autônoma, bem individualizada entre os desvios do comportamento sexual, foi definitivamente separada do homossexualismo, em 1964, por Benjamin e Gutheil.

A homossexualidade, como prática, é freqüentemente rejeitada pelo transexual que, sob o aspecto libidinal (psíquico), se comporta como heterossexual; mas, dependendo da predominância do envolvimento comportamental (sexualidade ou identidade), distinguem-se dois grupos fundamentais: "homossexual" e "obsessivo-compulsivo" 25

Este, o transexual, se considera membro do sexo oposto apenas gravado com o aparato sexual errado, o qual deseja ardentemente erradicar. ${ }^{26}$

Aquele, o homossexual, tem prazer em usar sua genitália como membros de seu sexo anatômico. Não tem desejo compulsivo de mudar de sexo, ao contrário do transexual. Acrescente-se que a síndrome transexual se inicia muito antes de o indivíduo ter consciência do que seja homossexualidade ou sexualidade genital.

No homossexual, os genitais são órgãos de prazer, ao passo que nos transexuais são órgãos de profundo desgosto. Sob o ponto de vista psicanalítico, o homossexual tem ego corporal masculino e ego psíquico feminino, sendo homem somaticamente. Os transexuais têm ambos os egos femininos e, somaticamente, são também homens. Os homossexuais consideram a relação sexual como homossexualidade (sentem-se homens e realizam o ato com outro homem). $\mathrm{O}$

24 Saldanha, P. H. e Olazabal, Luiza Campos, Valor do Estudo Citogenético no Transexualismo. Trabalho apresentado ao Simpósio patrocinado pelo Departamento de Urologia da Associação Paulista de Medicina, 1975.

25. Randel, J. B., Transvestitism and Transsexualism, Brit. Med. J. 2:1448, notas bibliográficas, 1959.

26. Walton, Terrence, When is a Woman not a Woman?, em New Law Journal 124/501, januaryjune, 1974.

Hamilton, William; e Walker, David W., Gender - Quaesto Ovid Juris?, Medicine, Science and the Law, v. 15, n. 2, 1975.

Drake, Donald C., Crossing the Sex Barrier, em Science Revue World, 1974. 
transexual vê essa relação no plano heterossexual, pois, considerando-se mulher, tem um homem como parceiro. ${ }^{27}$

Finalmente, não se confunde o transexual com o hermafrodita. $O$ hermafroditismo, também chamado intersexo, é uma condição congênita de ambigüidade das estruturas reprodutivas, de modo que o sexo do indivíduo não está plenamente definido como exclusivamente masculino ou feminino. Em outras palavras, coexistem, no hermafrodita, as glândulas genitais dos dois sexos: testículos e ovários. $^{28}$

Existe, por outro lado, o pseudo-hermafroditismo, onde o indivíduo somente apresenta glândulas sexuais de um sexo, consistindo sua anomalia nas vias genitais internas ou nos órgãos genitais externos "que exibem, no todo ou em parte, conformação semelhante à do sexo oposto ao das glândulas genitais de que são portadores" 29

Segundo alguns estudiosos, o hermafroditismo é um termo genérico que abrange todos os casos de intersexualidade e esta é um gênero do qual o hermafrodita verdadeiro é uma espécie. ${ }^{30}$

Enquanto o transexual suscita o problema de harmonizar a mente do indivíduo com o seu corpo, o hermafrodita suscita o problema de harmonizar o corpo do indivíduo ao seu verdadeiro sexo, através de alteração cirúrgica. Neste caso, isto é, tratando-se de genitália ambígua, não se discute o emprego da cirurgia reparadora nas más-formações e desvios de diferenciação dos genitais, sendo perfeitamente ético intervir cirurgicamente nestes pacientes, reconduzindo-os a um dos sexos, geralmente ao psicossocial ou ao que, em cada caso, oferecer melhores condições de técnicas operatórias. ${ }^{31}$

27. Rodrigues, Armando Canger, Aspectos Éticos do Transexualismo, trabalho apresentado no XI Congresso Brasileiro de Cirurgia Plástica, Belo Horizonte, 1974.

28. Moore Keith L., Interssexuality, em Canadian Medical of Ass. Journal, 83/756, 1960.

29. Fávero, Flamínio, Medicina Legal, v. 2, p. 187.

30. Epps, Dorina Rossetta G., depoimento constante de processo criminal n. 20/76 da $17^{\mathrm{a}}$ Vara Criminal de São Paulo.

31. Money, J. e Green, R., Transsexualism and Sex Reassignment, Johns Hopkins Univ. Press, Baltimore, 1968. 
No transexual o que se observa é que, em geral, o seu aparelho genital é normal e corretamente constituído, sendo que o desajuste que se observa é psíquico. $^{32}$

São deficientes as estatísticas referentes ao número de transexuais, mas o dr. H. Benjamin estima tal número em aproximadamente 10 mil, nos Estados Unidos.

\section{Histórico}

O transexualismo, anteriormente, era confundido com o transvestismo, tendo sido conhecido, sob várias denominações, em quase todas as civilizações e em todas as partes do mundo.

A ubiqüidade dessas entidades suscita a idéia de que não tenham representado uma corrupta manifestação de cultura, mas, quiçá, o resquício de uma antiga e natural sobrevivência do homem primitivo. ${ }^{33}$

Esses fenômenos foram conhecidos na Antigüidade. De fato, Heródoto descreveu-os como "doenças misteriosas dos citas", povo que vivia nas praias do norte do Mar Negro. Lá, homens, aparentemente normais, se vestiam com roupas femininas, faziam o trabalho das mulheres e afetavam, em geral, personalidade e comportamento feminino. A presença deles foi notada em uma imagem de Hércules, servindo sua amante Omphale, vestido com roupas femininas.

Demonstrando preocupação com o assunto, Hipócrates atribuiu o transvestismo entre os citas como tendo sido causado por um trauma mecânico, proveniente do excessivo cavalgar. Esse conceito foi revivido no começo do século XIX, quando a impotência e a feminilização encontradas entre os tártaros foram atribuídas a esse fator.

Em Roma antiga, particularmente no declínio, também foram conhecidos os travestis. No começo dos tempos modernos, os mais notórios foram três franceses: o irmão do rei Henrique III, o abade de Choisy e o proverbial Chevalier de Eon, cujo nome nos deu o termo eonismo como sinônimo de

32. Idem n. 27.

Pauly, I. B., Adult Manisfestations of Male Transsexualism,. Transsexualism and Sex Reassignment, ed. by Green, Money, Johns Hopkins Press, Baltimore, 1969, p. 56-7.

33. Block, Norman L., e Tessler, Arthur N., Transsexualism and Surgical Procedures. Reprint Medical Aspects of Human Sexualty, february, 1973. 
transvestismo. Este fenômeno tornou-se conhecido sob várias denominaçð̃es. Assim $\mathrm{Krafft}^{-E b i n g}{ }^{34}$ falava em metamorfose sexual paranóica; Ellis, em inversão sexoestética.

Em 1910, Hirschfeld, pela primeira vez, apresentou o termo transvestismo. Esse termo foi aceito em geral, embora sem a necessária discriminação entre o transvestismo real e o transexualismo. ${ }^{35}$

Lukianovicz sugeriu que o termo transvestismo fosse usado para o desvio sexual caracterizado pelo desejo de usar roupas do sexo oposto e o termo transexualismo aplicado àquelas raras vezes em que o transvestismo se apresente, ainda, com a característica do desejo mórbido de se submeter a uma intervenção cirúrgica de conversão sexual. ${ }^{36}$

A pletora de nomes dada a esta última entidade foi superada por $\mathrm{H}$. Benjamin, ${ }^{37}$ que a denominou transexualismo, hoje divulgado através dos jornais, das revistas, da literatura médica e de publicações legais.

Assim individualizada e conhecida, foi crescendo a importância médica do transexualismo, mormente em função da terapêutica hormonal e, especialmente, cirúrgica.

III - A Cirurgia de Conversão como Tentativa de Solução do Problema

1. Preliminares médico-legais e éticas

O mais notório caso de cirurgia para a redeterminação sexual foi o de George Jorgensen, americano, que se tornou Christine Jorgensen, em 1952, tendo se submetido à operação na Dinamarca. ${ }^{38}$

A primeira clínica, nos EUA, para o tratamento de transexuais, foi estabelecida na Escola de Medicina da Universidade Johns Hopkins, em 1966,

34. Kraff-Ebing, R., Psychopathia Sexualis, Milano, notas bibliográficas, 1953. 1936.

35. Hirschfeld, M., Sexuals Anomalies and Perversions. London; F. Alder, notas bibliográficas,

36. Lukianovicz, N., Survey of Various Aspects of Transvestism in the Light of Our Present Knowledge, J. New Ment. Dis., notas bibliográficas, 1959.

37. Benjamin, H., The Transsexual Phenomenon. New York, The Julian Press, 1966.

38. Wălinder, Jan, Médico Legal Aspects of Transsexualism in Sweden, Johns Hopinks Press, Baltimore, p. 461, 1969. 
através da Gender Identity Clinic, na qual foram avaliados e examinados várias centenas de transexuais, sendo que mais ou menos 100 foram submetidos à cirurgia de redeterminação de sexo.

O transexual apresenta um quase patognomônico desejo obsessivo de "correção" cirúrgica do sexo, o qual, quando não atendido, é fonte de atitudes psicopatológicas reacionais, tais como: automutilação peotônica e tentativas de suicídio, nos casos extremos. ${ }^{39}$

Do transexualismo, por ser muito raro, pode-se dizer que não é reversível, nem pelo tratamento hormonal, nem por qualquer outro como o psiquiátrico que, como já observamos, é ineficaz. A propósito, o dr. Anke A. Ehrhart, professor de Psiquiatria da Universidade de Buffalo, $\mathrm{NY},{ }^{40}$ afirma que, como não se conhecem ainda as causas dessa entidade, é impossível diagnosticá-la e curá-la efetivamente.

É conveniente esclarecer que o tratamento hormonal consiste em ministrar estrógenos e progesterona nos pacientes anatomicamente masculinos e testosterona, nos anatomicamente femininos. Este tratamento não apresenta qualquer resultado, visto que não age sobre a personalidade do transexual, nem lhe extingue $o$ desejo de assumir totalmente o sexo oposto, ao qual se julga pertencer. Ihlenfeld ${ }^{41}$ diz que o número de mulheres transexuais, isto é, que desejam mudar de seu sexo para homem, em comparação com os transexuais masculinos, está na proporção de 8 para l, ou seja, o número de transexuais masculinos é 8 vezes maior do que o de mulheres. Outras estatísticas demonstram uma proporção de 4 para 1.

Quanto ao tratamento psicanalítico, a maior dificuldade consiste na resistência apresentada pelo paciente. Praticamente, o transexual primário não se sujeita a esse tratamento, porque não quer readaptar sua personalidade.

Outra dificuldade reside no próprio terapeuta, pois se este não acreditar que pode ajudar o transexual, isso redundará em um impasse analítico, com o conseqüente fracasso do tratamento.

39. Pauly, I. B., Adult Manifestations of Male Transsexualism, Transsexualism and Sex Reassignment, ed. by Richard Green and John Money, Johns Hopkins Press, 1969.

40. Ehrhart, A. A., Transsexualism and Cirurgical Procedures, notas bibliograficas.

41. Ihlenfeld, Charles L., When a Woman Becomes a Man, Sexology Magazine, june, 1972. 
Por isso, os EUA e alguns países da Europa optaram pela cirurgia. ${ }^{42}$ Mas, antes de qualquer intervenção cirúrgica, durante mais ou menos dois anos, o paciente, seja do sexo feminino ou do masculino, deverá viver o papel do sexo oposto, a fim de sentir-se "socialmente aceito"

Neste tratamento complexo que se estende, às vezes, por mais de dois anos, administram-se hormônios, cujo efeito é a obtenção das desejadas características sexuais secundárias. $\mathrm{O}$ tratamento envolve reajustamento físico, social e emocional. Somente, então, poder-se-á pensar em alteração cirúrgica dos genitais. $^{43}$

Comprovadamente malogrados os tratamentos, dir-se-ia que a única solução, para resolver o conflito em que vive o transexual, seria a cirurgia de conversão.

A cirurgia consiste na ablação dos órgãos sexuais masculinos, abrindose no períneo, mediante incisão, uma fenda, ou seca, a neovagina.

Desse ato cirúrgico resulta, para o paciente, a perda irreparável de seus orgãos genitais, com a extinção de suas respectivas funções.

Com isto, o paciente não muda, realmente, de sexo, pois não há possibilidade de implantação de órgãos genitais internos femininos, como o útero, os ovários e anexos, destinados à procriação.

Neste ponto, devemos nos lembrar de conseqüências de extrema importância que podem ocorrer, como, por exemplo, o arrependimento pósoperatório do paciente; ou a neovagina, cirurgicamente implantada, na melhor das hipóteses, não satisfazer à libido do transexual, nem tampouco a do parceiro, como naturalmente aconteceria em condições normais. ${ }^{44}$

42. Transsexualism, Sex Reassignment Surgery and the Law, Cornell Law Review, v. 56:963, p. 970, 1971.

Cunnan and Shapiro, Law, Medicine and Forensic Science, $2^{\mathrm{a}}$ ed., p. 836, 1970.

Sturup, Georg K., Legal Problems Related to Transsexualism and Sex Reassignment in Denmark, Johns Hopkins Press, Baltimore, p. 453, 1969.

43. Transsexuals in Limbo, Maryland Law Review, v. 31/236, 1971.

44. Guidelines for Transsexuals, Erickson Educational Foundation Publication.

Rodrigues, Armando Canger, Aspectos Éticos do Transexualismo, trabalho apresentado no XI Congresso Brasileiro de Cirurgia Plástica, Belo Horizonte, 1974. 
Por razões médicas, bem como legais, os cirurgiões não farão a operação de redeterminação do sexo num menor, por estar esse tratamento vedado; no entanto, é permitido a eles ministrar, aos menores, tratamento hormonal. ${ }^{45}$

$\mathrm{Na}$ Holanda, Suécia, Dinamarca e Inglaterra, a operação de redeterminação sexual e a pertinente terapia são acessíveis, gratuitamente, a cidadãos e residentes de longa permanência. ${ }^{46}$

Acrescente-se, aqui, um problema médico-legal e religioso que reside na situação resultante da esterilidade causada pela operação que estaria, também, contra os cânones da Igreja.

Com respeito ao aspecto ético do transexualismo, visto como um desvio da normalidade, cuja patologia imprime alto grau de sofrimento ao transexual, este se aproximaria mais da normalidade sexual por repudiar 0 homossexualismo e considerar sua esfera erótica heterossexual.

A problemática ético-jurídica do transexualismo é ampla e não totalmente resolvida, ou, pelo menos, aceita em todos os países. Nem mesmo a validade da correção cirúrgica é acatada com unanimidade. O próprio Gutheil referese que "a operação só satisfaz o desejo de castração do individuo, sem propiciar beneficio à sua situação psicológica" Tolentino, por sua vez, a considera "uma tentativa inútil e superficial" ${ }^{47}$

Diante das constantes e reiteradas solicitações de ajuda promovidas pelos transexuais de todo o mundo, plenamente conscientizados dos seus problemas, os congressos e tribunais de Ética Médica têm-se pronunciado, ora, favoravelmente, ora desfavoravelmente, à cirurgia amputativa dos genitais masculinos, frente aos problemas morais biológicos, clínicos, psicossociais e jurídicos que são suscitados.

No Brasil, os conselhos de Medicina não se pronunciaram oficialmente sobre o problema e seus órgãos supervisores, julgadores e disciplinadores da Ética, que visam ao prestígio e ao bom conceito da Medicina e do

45. Legal Aspects of Transsexualism, Erickson Educational Foundation Publication. Kennedy, Ian McColl, Transsexualism and Single Sex mariage, Anglo American Law Review, 1973.

46. Bekendtgreese on Sterilisation of Kastration, n. 98, 1976, Justits Ministeriets. (Notas bibliográficas).

Sturup, Georg K., Legal Problems Related to Transsexualism in Denmarck, Johns Hopkins Press, Baltimore, p. 453, 1969.

47. Rodrigues, Armando Canger - Aspectos Éticos do Transexualismo. Trabalho apresentado no XI Congresso Brasileiro de Cirurgia Plástica, B. Horizonte, 1974. 
médico, não são dotados de poder sobre os doentes. Sua ação se exerce sobre o comportamento do médico, fundada no Código de Ética Médica. ${ }^{48}$

Neste Código, vamos encontrar os seguintes dispositivos, nos quais se enquadram as terapêuticas propostas para o transexualismo:

"Art. 32 - Não é permitido ao médico indicar ou executar terapêutica ou intervenção cirúrgica desnecessária ou proibida pela legislação do País.

Art. 51 - São lícitas as intervenções cirúrgicas com finalidade estética, desde que necessárias ou quando o defeito a ser removido ou atenuado seja o fato de desajuste psíquico.

Art. 52 - A esterilização é condenada, podendo entretanto ser praticada em casos excepcionais, quando houver precisa indicação, referendada por mais de dois médicos ouvidos em conferência."

Calcado no Código de Ética Médica, pergunta-se: é lícita a operação de conversão sexual? O Conselho Federal de Medicina, através de seus conselheiros, declarou a inadmissibilidade de tal operação. A Associação Paulista de Medicina, por sua diretoria, limitou-se a recomendar o tratamento do transexual, mediante conferência médica, nos termos do Código de Ética Médica. ${ }^{49} \mathrm{O}$ Conselho Regional de Medicina de São Paulo desaprova, totalmente, tais cirurgias plásticas, pois que elas ofendem valores éticos, que as sociedades médicas do Brasil devem preservar.

Segundo o relatório do IV Congresso Brasileiro de Medicina Legal, reunido na cidade de São Paulo, de 08 a 12/12/1974, foi apontado o seguinte:

a) que, sob o ponto de vista anatômico, a operação de transexual não é corretiva, mas mutiladora;

b) que, em conseqüência, constitui "lesão, sob o ponto de vista penal"

Entendem que a operação cogitada é da natureza de cirurgia plástica, mas classificada como mutiladora, o que ab initio afasta-a dos termos do art. 51 , do Código de Ética Médica.

O Instituto Médico Legal de São Paulo, interpretando o art. 51, do Código de Ética Médica, acredita que, no caso dos transexuais, a intervenção terapêutica necessária não seria uma cura radical, mas atenuadora do desajustamento psíquico.

\section{Código de Ética Médica.}

49. Associação Paulista de Medicina, Jornal O Médico Paulista, publ. da primeira quinzena de dezembro de 1976. 
O XI Congresso Brasileiro de Cirurgia Plástica, que teve lugar em Belo Horizonte, em 11/05/1974, em uma de suas conclusões, afirma:

"Quem quiser mudar de sexo no Brasil terá de esperar que o Congresso Nacional aprove uma lei autorizando esse tipo de cirurgia"

O Conselho Regional de Medicina de Santa Catarina encaminhou ao Conselho Federal de Medicina um caso para que fosse examinando, e este, por manifestação unânime dos seus membros, concluiu que a matéria cuidava exclusivamente de cirurgia mutiladora e jamais restauradora do ponto de vista psicossocial, motivo pelo qual não tinha qualquer finalidade terapêutica. Essa decisão foi devidamente encaminhada aos Conselhos Regionais e às escolas médicas para conhecimento e natural cumprimento de seus termos. ${ }^{50}$

Por inexistência de norma legal expressa, entende-se que seriam aplicadas à questão, por analogia, as normas e princípios recentemente estabelecidos para os transplantes de órgãos.

A Lei n. 5.479, de 10/08/1968, em seu art. 10, permite a disposição de "órgãos e partes do próprio corpo vivo, para fins humanos e terapêuticos" $\mathrm{E} \S \S 1^{\circ}$ e $2^{\circ}$, do mesmo artigo, determina a necessidade de autorização do disponente e que a extração autorizada não implique em prejuizo ou mutilação grave para o disponente.

Verifica-se, no caso, que a cirurgia subjudice produzirá mutilação gravíssima, e o objetivo final do transexual (seja de homem para mulher ou de mulher para homem), que é mudar de sexo, não será atingido fisicamente.

Do ponto de vista da deontologia médica, o Conselho Federal de Medicina, como já mencionamos, condena, por antiética, a operação plástica mutiladora. $^{51}$

Um dos aspectos que, inicialmente, ofereceu obstáculos ao tratamento cirúrgico dos transexuais, foi a aceitação tácita de que o desajuste desses pacientes, sendo psíquico, estava no cérebro e a conduta terapêutica mais lógica seria endereçálos aos psiquiatras e não aos cirurgiões.

Os trabalhos, todavia, têm demostrado que, no transexual adulto, a terapêutica psiquiátrica é rejeitada pelo próprio paciente, como já referimos anteriormente.

50. Ética Médica e Lei Penal, O Estado de S. Paulo, em 12-03-1976.

51. Salgado, Murilo Rezende - O Transexual e a Cirurgia para a Pretendida Mudança de Sexo, R.T. $491 / 241$. 
Sendo verdadeira essa assertiva, a Medicina contará com a opção de aceitar o tratamento cirúrgico, ${ }^{52}$ levando-se em consideração ainda os motivos apresentados pelos transexuais, entre os quais o sofrimento emocional de ter órgãos masculinos constantemente ultrajando sua psique feminina; o desejo de ter relações íntimas de "forma normal"; o desejo de imunidade legal ao personificarem o sexo oposto e, finalmente, o objetivo maior: o casamento.

Afirma o dr. Charles Ihlenfeld que, de abril de 1969 a julho de 1972, observou, em sua prática privada, mais de 500 pacientes com problemas de disforia sexual. Por sua vez, o dr. Harry Benjamin relacionou 1.200 pacientes, durante 25 anos, até junho de 1975. Dessa série, mais de 300 pacientes submeteram-se a processo cirúrgico para a redeterminação de sexo, após rigorosa diagnose clínicopsicológica. O dr. John Money, professor de Psicologia da Universidade Johns Hopkins, afirma que o número de transexuais operados nos EUA e Canadá ultrapassa 1.000 casos. A Gender Identity Clinic observou que, de $11 \%$ a $18 \%$ dos pacientes que solicitaram a citada cirurgia, obtiveram-na.

Entre essas clínicas, que nos dizeres do dr. R. Granato, médico urologista em Elmhurst, Nova Iorque, são em número de 20, temos a da Stanford University, em Palo Alto, Califórnia e a Johns Hopkins Hospital, em Baltimore, Maryland.

Mas, aqui no Brasil, como essa cirurgia foi, e ainda é, eticamente condenada, afigura-se-nos que outro meio deverá ser encontrado.

Para sintetizar o controvertido tema deste capítulo, aflora-nos ao espírito uma pergunta de relevante importância:

transexual?

$E$ É de fato, essa cirurgia, a solução ideal para o problema do

52. Benjamin, Harry; e Ihlenfeld, Charles L., Transsexualism, American Journal of Nursing, v. 73, n. 3, march, 1973. 


\section{Conseqüências}

A primeira pergunta (talvez a única) a ser respondida da resposta decorrendo todas as conseqüências da cirurgia de conversão - é esta: a cirurgia tem $o$ efeito de mudar o sexo do individuo, isto é, transforma efetivamente o homem em mulher ou a mulher em homem?

Se a resposta a esta pergunta fosse afirmativa, seria possível, talvez, defender a cirurgia de conversão e, desde logo, pugnar pela adoção de uma legislação que regulasse todos os fatos que envolvessem o transexual após sua submissão à cirurgia.

$\mathrm{Na}$ verdade, porém, não nos parece que a resposta àquela pergunta possa ser outra que não a negativa. Em outras palavras, a cirurgia pode mudar a aparência, mas não o seu sexo, daí decorrendo conseqüências de várias ordens, que procuraremos resumir em seguida.

\section{IV - Direito Comparado}

\section{A solução do problema na esfera civil}

\section{a. Considerações sobre o casamento de transexuais}

Não existe, presentemente, uma jurisprudência formada, nos EUA, com respeito à validade dos casamentos contraídos com transexuais pós-operados. Contudo, do ponto de vista prático, este problema só surgirá quando pedidos de divórcio ou de anulação forem efetuados. ${ }^{53}$

A questão sobre se o pós-operatório transexual deve revelar ao seu prospectivo consorte a cirurgia a que se submeteu tem, primordialmente, implicações éticas e legais. Caso não revele esta condição irá suscitar fundamentos para a anulação ou divórcio, pois que tal casamento será considerado como fraudulento. Já houve caso, como adiante citaremos, em que a anulação do casamento foi concedida com fundamento na esterilidade do cônjuge transexual operado. E esta se constitui

53. Guidelines for Transsexuals, Erickson Educational Foundation Publication.

Transsexualism, Cornell Law Review, v. 59:963, 1971.

Sherwin, Robert Veit, Legal Aspects of Male Transsexualism. Johns Hopkins Press, Baltimore, 1969.

Brent, Gail, Some Legal Problems of the Post Operative Transsexual. Journal of Family Law, v. 12, (1972-1973). 
em um forte argumento contra a cirurgia que priva o indivíduo de sua capacidade reprodutiva, no caso de disforia sexual não incluir a esterilidade. ${ }^{54}$

A propósito, no caso Corbett v. Corbett, ${ }^{55}$ o juiz inglês Ormrod afirmou que a cirurgia da reatribuição de sexo não muda o sexo legal do transexual; portanto, o casamento de transexual (de masculino para feminino) com pessoa de seu sexo de origem torna-se, legalmente, um casamento inexistente. Continuando, afirmou o juiz que a relação sexual, usando um canal criado artificialmente pela plástica genital, não poderia ser descrita como vera copula, não sendo possível, pois, consumar o casamento. ${ }^{56}$

No nosso Direito, haverá de ser extremamente difícil que cheguem a se casar pessoas do mesmo sexo, em face das solenidades e publicidades que cercam a realização do ato.

Para Clóvis Bevilacqua, a suposição não merece ser considerada; poder-se-á verificar, apenas, em casos de hermafroditismo ou deformações. ${ }^{57}$

b. Fundamentos para o divórcio de transexuais

O caso acima mencionado, de Corbett v. Corbett, é um claro exemplo do problema da validade do casamento do transexual operado, com pessoa de seu

54. The Weekly Law Reports. Publ. New York, 1970.

Sherwin, Robert Veit, Legal Aspects of Male Transsexualism. Johns Hopkins Press, Baltimore, 1969.

55. O caso Corbett v. Corbett foi julgado na Inglaterra em 1970. Um transexual, de masculino para feminino, de nome April Ashley, submeteu-se à cirurgia de conversão em 1960. Em 1963, casouse com Arthur Corbett; April Ashley e Arthur Corbett estiveram juntos durante 14 dias no espaço de 3 meses, ao fim dos quais Arthur Corbett propôs ação de anulação de casamento, baseando-se nos seguintes fundamentos:

a) a "mulher" pertencia ao sexo masculino;

b) o casamento não se consumara.

Em reconvenção, alegou April Ashley a impotência de Arthur Corbett ou sua intenção de não consumar o casamento. Em sua decisão, afirmou o juiz que o sexo é estabelecido no nascimento; que a "mulher" tinha cromossomas XY, isto é, cromossomas masculinos; antes da operação tinha as gônadas masculinas e a genitália externa masculina, pertencendo, pois, ao sexo masculino, sendo psicologicamente um transexual. Conclui que a "mulher" continuava sendo homem e não podia desempenhar o principal papel da mulher no casamento, concedendo, por conseguinte, a anulação requerida.

56. James, Thomas E. PHD, Legal Issues of Transsexualism in England. p. 27.

57. Coelho, Vicente de Faria, Nulidade e Anulação do Casamento. Livraria Freitas Bastos S. A., 
sexo de origem, na Inglaterra. Se o casamento não é legalmente válido, torna-se necessária sua anulação ou sua dissolução pelo divórcio.

Poderá o divórcio basear-se (evidentemente nas legislações que o admitem) no fundamento da impotência, visto que os envolvidos são incapazes de qualquer relação sexual normal, especialmente no caso do transexual de feminino para masculino.

Tribunais americanos têm, também, aceitado o fundamento de crueldade intolerável, suficientemente amplo e genérico para cobrir a hipótese. ${ }^{58}$

Com respeito ao adultério, a cirurgia torna-o fisicamente impossível, visto que remove os órgãos sexuais necessários para cometê-lo com pessoa do sexo oposto ao próprio sexo cromossômico. As relações extramaritais, portanto, não podem ser adulterinas, mas sim homossexuais. ${ }^{59}$

Outro fundamento tradicional para o divórcio nos EUA seria a fraude, pois, como já dissemos, o transexual deve revelar ao seu parceiro sua mudança de sexo e sua conseqüente esterilidade, a exemplo do caso de Frances B. v. Mark B. ${ }^{60}$

c. Dificuldades para contrair matrimônio

Internacionalmente, no capítulo dos impedimentos matrimoniais, refere-se a lei àqueles relativos ao parentesco, às pessoas já casadas, aos menores, ao coactos, silenciando, porém, a respeito dos transexuais.

À primeira vista, dir-se-ia que, uma vez que a lei não proíbe, poderiam os interessados obter licença para o casamento.

Não é, todavia, o que ocorre. O Estado retém o direito de decidir quais os casamentos que considera válidos. Como o casamento se submete a normas de ordem pública, havendo, desde logo, todo um processo de habilitação, não poderia 0 transexual satisfazer às exigências legais sem retificar seu registro civil ou sem burlar oficiais de registro menos avisados (o que tem ocorrido com certa freqüência nos Estados Unidos). ${ }^{61}$

58. U.S. Supreme Court Proceedings. The Family Law Reporter, march 11, 1975.

59. Transsexualism, Cornell Law Review, v. 56:963.

New York Supplement - 293 N.Y.S., 2d. 834; 293 N.Y.S., 2d. 557; 355 N.Y.S., 2d. 712; 325 N.Y.S., 2d. 499; 347 N.Y.S., 2d. $515 ; 314$ N.Y.S., 2 d. 668.

60. No caso Frances B. v. Mark B., porém, decidiu o Supremo Tribunal de Nova lorque anular o casamento por ofensa à finalidade de procriar, ao invés de levar em consideração a fraude de uma das partes e não revelar a sua transexualidade.

61. Transsexualism, Cornel Law Review, v. 56:963. 
Dúvidas persistem, de outra parte, sobre a possibilidade de impugnação do casamento, se os interessados resolverem permanecer casados.

Quer-nos parecer que, se o casamento somente se realizou através de burla ou fraude, deveria o Ministério Público intentar sua anulação. ${ }^{62}$ Esta legitimação, porém, a nosso ver, inexistiria, se o transexual houvesse obtido retificação do seu registro civil, mesmo porque temos notícia do reconhecimento da validade de tais casamentos, como no caso decidido pelo Tribunal de New Jersey. ${ }^{63}$

\section{d. Relacionamento entre pais transexuais e filhos}

Nos EUA, o transexual casado, que decide se submeter à operação para a redeterminação do sexo, deve procurar, ab initio, assistência legal. Isto é de suma importância, não-só respeitante a seu cônjuge, como aos filhos, se houver. Em todo caso a grande maioria de cirurgiões não efetuará a operação até que o divórcio seja obtido. ${ }^{64}$

Consideremos, sob este ítem, o caso do transexual que teve filhos antes da mudança de sexo. Parece-nos que um prévio casamento heterossexual seria uma prova contra-indicativa de transexualidade verdadeira. As emoções, necessidades e circunstâncias que afetam os seres, porém, nem sempre se coadunam com a norma teórica.

Um caso decidido pela Tribunal de Apelação do Colorado, Estados Unidos, ilustra bem a questão. ${ }^{65}$

62. The Law and Transsexualism, Connecticut Law Review, v. 7:288, 1975.

63. No caso de um transexual operado de masculino para feminino, que se casou com um homem, decidiu um tribunal de New Jersey, Estados Unidos, em ação de alimentos proposta contra o homem "que a abandonara", que o casamento era válido, em razão do conhecimento que o marido tinha da mudança de sexo de sua "mulher" efetuada antes do casamento, condenando-o ao pagamento da pensão alimentícia.

Afirmou ainda o tribunal que, tendo sido efetuada a operação do transexual, não tinha a sociedade $o$ direito de proibir que ele levasse uma vida normal.

64. Legal Aspects of Transsexualism, Erickson Educational Foundation Publication.

65. Um transexual de mulher para homem tinha 4 filhas menores de um casamento anterior. Divorciou-se e a guarda das filhas the foi conferida. Em seguida, submeteu-se à cirurgia de reatribuição de sexo e casou-se com uma mulher que trouxe para o casamento um filho de casamento anterior. $\mathrm{O}$ ex-marido do transexual requereu a mudança de guarda das filhas. A sentença de $1^{\mathrm{a}}$ Instância foi-lhe favorável mas, em apelação, foi ela reformada, decidindo o tribunal que as meninas permaneceriam com a mãe natural (agora homem) em razão do interesse e bem-estar das menores.

Holloway, John P., Transsexuals and Their "Legal Sex", Johns Hopkins Press, Baltimore, 1969 
A conclusão que se pode extrair do caso acima citado é que não existe razão categórica para classificar o transexual como pai ou mãe inadequados. Em outro caso, porém, ao qual iremos nos referir mais adiante, ${ }^{66}$ ficou decidido que um professor transexual operado causava danos psicológicos às crianças, de tal forma que era justificada a sua dispensa.

\section{e. Direitos da mulher e filhos do castrado na Dinamarca}

Quanto ao direito da mulher do castrado a obter indenizações em relação ao cônjuge castrado ou ao médico que efetuou a cirurgia, o entendimento do Ministério da Justiça é pela negativa. Contudo, a questão em apreço deve ser decidida pelos tribunais.

Relativamente à guarda dos filhos do casal, é de se apontar que tal questão não foi suscitada ainda perante o Ministério da Justiça dinamarquês.

Acrescente-se que a castração não estabelece qualquer impedimento quanto ao direito de sucessão atribuído ao castrado, segundo a lei dinamarquesa.

- Casamento de transexual na Dinamarca

A pessoa que haja sofrido cirurgia de reatribuição sexual pode requerer licença para casar-se com pessoa pertencente ao seu sexo de origem.

\section{Esterilização}

Quanto à esterilização, qualquer pessoa que tenha atingido 25 anos de idade e for residente na Dinamarca poderá obtê-la. Se for menor de 25 anos, há necessidade de permissão de órgãos especializados. ${ }^{67}$

\section{f. Herança}

No Direito pátrio, a questão da herança não suscita grandes problemas para o transexual, uma vez que, comprovada sua filiação, terá direito à legítima, tanto no caso de o ascendente ter falecido ab intestato ou não.

No Direito americano, de modo geral, em razão da amplíssima liberdade de testar, o problema surge no caso de o testador atribuir propriedades a filho ou filha. Após a mudança de sexo, através da cirurgia de conversão, pode o herdeiro ver-se impossibilitado de recolher seu quinhão.

66. Transsexualism, Cornell Law Review, v. 56:963.

67. Sturup, Georg K., Legal Problems Related to Transsexualism in Denmark. 
Nessa hipótese, haveria necessidade de verificar com cautela a intenção do testador. É possível que a disposição testamentária tenha mesmo tido a finalidade de impedir, ou tentar impedir, que o filho ou a filha se submeta à cirurgia de conversão, permanecendo o problema de se saber se o juiz homologará, ou não, as restrições impostas pelo testador. ${ }^{68}$

\section{g. Identidade legal e registro civil}

Quer-nos parecer que este é um dos maiores, se não o maior, problema do transexual pós-operado.

$\mathrm{O}$ primeiro aspecto do problema diz respeito à mudança de nome. $\mathrm{O}$ prenome do paciente, via de regra, é inadequado após a cirurgia.

O nosso Direito consagrou o princípio da imutabilidade do nome, o qual abrange o prenome e patronímico.

No entanto, essa regra não é absoluta. Assim, de acordo com a nova Lei de Registros Públicos n. 6.015, de 31/12/73, com as alterações introduzidas pelas leis ns. 6.140 , de 28/11/74 e 6.216, de 30/06/75, em seu art. 58, o prenome é imutável, contudo poderá ser mudado, quando expuser ao ridículo o seu portador (art. 55, § único), assim como, retificado, no caso de erro gráfico (art. 58, § único).

$\mathrm{O}$ art. 56 admite a alteração do nome, desde que não prejudique os apelidos de familia; entendemos, então, que pode haver alteração do sobrenome parte do nome completo que medeia entre o pronome e o patronímico ou apelidos de família mas não pode haver alteração do patronímico.

No entanto, existem causas justificativas da alteração e mudança do patronímico, assim: no caso do casamento, desquite, reconhecimento de filhos, no caso do art. 57 e seus $\S \S$, mudança de nome dos ascendentes ou do marido; omissão de apelido de família quando do registro; condição de filho de criação; condição de tutelado; adoção; mudança de patronímico estrangeiro para nacional. ${ }^{69}$

Verificando, assim, que o nosso Direito, neste particular, afasta qualquer pretensão do transexual à mudança do prenome, conforme o que acima foi dito.

Quanto à mudança do sexo no registro, em nossa sistemática dos registros públicos, somente são admissíveis retificações de assentos que contenham

68. The Law and Transsexualism, Connecticut Law Review, v. 7.288, 1975.

69. França, Rubens Limongi, Do Nome Civil das Pessoas Naturais, Rev. dos Tribunais, p. 193. 
erros ou inexatidões relativamente ao sexo da pessoa natural, em casos de hermafroditismo ou naqueles em que, por anomalia superveniente, fique preponderando um sexo sobre o outro. É a lição da doutrina. ${ }^{70}$

Segundo o direito consuetudinário nos EUA, o indivíduo pode assumir o nome que quiser, desde que não interfira no direito de outrém e não haja intenção de fraude ou dolo. A mudança do nome é obtida através de processo meramente administrativo, servindo de base para o pedido o fato de ser o nome lingüisticamente difícil, ou sendo tal que provoque embaraço, ridículo, confusão ou identificação errônea. ${ }^{71}$

Não tem sido muito difícil, pois, ao transexual, obter a mudança de seu prenome, fazendo a ressalva de que, em alguns Estados, tem sido possível a mudança do nome e do sexo nos registros de nascimento, enquanto em outros somente a mudança de nome tem sido permitida. Contudo, a maioria dos Estados americanos, aparentemente, não farão a citada mudança de status, oficialmente, a não ser que se prove erro na certidão original. ${ }^{72}$

No entanto, a questão é controvertida. Atualmente, somente os Estados de Arizona, Illinois e Louisiana possuem leis que regulamentam as alterações na certidão de nascimento, no caso específico dos transexuais. Tais Estados fornecem ao indivíduo um documento oficial indicando seu sexo, sem menção ao sexo anterior. A mais complexa legislação é a do Estado de Louisiana, onde há todo um capítulo dedicado à "Emissão de Uma Nova Certidão de Nascimento Depois da Mudança do Sexo Anatômico Através de Cirurgia" O procedimento requer petição ao mesmo tribunal, ao qual foi pedida a mudança do nome. Antecipando problemas do transexual com respeito ao Direito da Família, a lei exige que o cônjuge seja parte na ação. Depois da expedição da nova certidão, devem a certidão original, a petição e a sentença, ser seladas e arquivadas no cartório competente. Este processo selado somente poderá ser aberto a requerimento do interessado, acompanhado de ordem judicial, prolatada pelo Juízo que admitiu a nova certidão. ${ }^{73}$

70. Lopes, Serpa, Curso de Direito Civil, v. I, p.327.

71. Legal Aspects of Transsexualism, Erickson Educational Foundation Publication.

72. Idem

Change of Sex on Birth Certificates for Transsexuals, Bulletin of New York Academy of Medicine, v. 42, n. 8, 1966.

73. Transsexualism, Cornell Law Review, v. 56:963.

Arizona Reviewed Statute annotated, 36-326, 1976. 
Os tribunais da Louisiana restringem-se a três requisitos para a emissão da nova certidão: diagnóstico apropriado, tratamento apropriado e alteração anatômica bem-sucedida. ${ }^{74}$

O Estado do Arizona acompanha o Estado de Illinois ao admitir a mudança do registro de nascimento, exigindo que a iniciativa seja tomada por médico devidamente licenciado e colocando a decisão final nas mãos de um oficial administrativo. Ao contrário dos Estados de Illinois e da Louisiana, porém, o Estado do Arizona exige a contagem cromossômica como critério para a mudança do sexo na certidão de nascimento. ${ }^{75}$

Em outros Estados essas modificações são obtidas através de seus canais administrativos. Os Estados como Arkansas, Colorado, Flórida, Hawaí, Maryland, Michigan, Minnesota, New York, Ohio, Texas têm seguido as diretrizes dos três acima-mencionados com respeito à questão.

No Canadá, não há disposições à respeito do assunto. ${ }^{76} \mathrm{~A}$ Inglaterra admite a mudança do registro de nascimento no caso de "erro físico" ${ }^{77} \mathrm{Na}$ Escócia, é absolutamente impossível a mudança de registro, o mesmo ocorrendo na Alemanha (onde, aliás, a cirurgia de reatribuição sexual é ilegal). ${ }^{78}$

Na Dinamarca, a alteração do prenome é concedida pelo Ministério da Justiça, quando o requerente é castrado, quando foi esterilizado ou quando se estabeleceu a impossibilidade de procriar. A castração necessita de permissão outorgada pelo Ministério da Justiça. Não há, na lei dinamarquesa, disposições sobre a situação do casal, quando um dos cônjuges se submete à castração. Existe uma presunção, fundamentada em sentença, não-publicada, proferida pelo Tribunal dos Magistrados de Copenhague, que determina ser o casamento considerado nulo a partir da cirurgia castradora. $\mathrm{O}$ tribunal considerou, à vista da certidão médica

74. Atlantic Reporter.

75. Arizona Reviewed Statute annotated, 36-326, 1976.

76. Canadian Medical Association Journal, 83-756, 1970.

Kouri, Robert P., Comments on Transsexualism in the Province of Quebec., Revue de Droit Civil - Université de Sherbrooke - Province of Quebec, 1973.

77. Anglo American Law Review, 1973

James, E. Thomas, Legal Issues of Transsexualism in England, Erickson Educational Foundation Publication.

78. Meyers, David William, Problems of Sex Determination and Alteration, Médico-Legal Journal, 1968. 
exigida, relativamente à condição física e psíquica da pessoa, que tal pessoa se tornara incapaz de permanecer casado com sua mulher. ${ }^{79}$

\section{h. Decisões prolatadas por Tribunais Alemão e Suíço}

Existem registros de decisões de Tribunal de Berlim e de Tribunal de Frankfurt, concluindo que a alteração do sexo através de cirurgia não pode ser aceita pelo tribunal, seja com o propósito de alterar passaporte (Berlim), seja para afastar possível acusação de homossexualidade (Frankfurt).

Em 1963, foi julgado o seguinte caso nos tribunais suiços: um homem casado, pai de um filho, automutilou-se. Em seguida, obteve o divórcio e submeteuse à cirurgia para transformar-se em mulher. O tribunal reconheceu seu status feminino. ${ }^{80}$

i. Casos de alteração de sexo Decisões prolatadas por Juízes e Tribunais Brasileiros

No Brasil, temos conhecimento de alguns casos de pedido de mudança de nome e de sexo no registro de nascimento, em virtude de cirurgia de reatribuição de sexo. O primeiro deles chegou a receber decisão favorável da Vara de Registros Públicos da Capital de São Paulo; eis que esse MM. Juízo autorizou a retificação do prenome do autor bem como a averbação, no registro, de que se tratava de pessoa do sexo feminino.

Em recurso interposto pelo curador de Registros Públicos ${ }^{81}$ decidiu 0 Tribunal de Justiça de São Paulo, através de uma de suas câmaras, acolher a preliminar de incompetência do Juízo da Vara de Registros Públicos por se tratar de ação de Estado, de competência, portanto, da Vara da Família e Sucessões, sem pronunciar-se sobre o mérito do feito.

79. Sentença proferida pelo Tribunal dos Magistrados de Copenhague, 24 de junho de 1955.

Sarnoff, A. Mednik Diretor-Médico do Psykologisk Institut K. Benhavn, Denmark Carta juntada aos autos do processo criminal n. $20 / 76$ da $17^{\mathrm{a}}$ Vara Criminal.

Walinder, J. T. - A Law Concerning Sex Reassignment of Transsexuals in Sweden, Arch. Sex Bahav., 1976.

80. Transsexualism, Cornell Law Review, Medicolegal Aspects of Transsexualism, Johns Hopkins Press, Baltimore, 1969. Foreign Juridiction, v. 56:963.

81. Razð̃es da apelação do dr. curador de R.P. Processo n. 1.118/70, cujo acórdðo foi publ. na R.T. 444. 
Esse caso teve continuidade através da remessa dos autos a uma das Varas da Família e Sucessões, onde foi julgado improcedente. Tendo o autor recorrido ao Tribunal de Justiça, este decidiu, através de uma de suas câmaras,

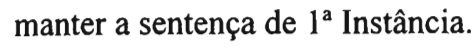

Podemos, ainda, relacionar, neste passo, o acórdão de $2^{\mathrm{a}}$ Câmara Cível do Tribunal de Justiça de São Paulo, prolatado na Apelação Cível n. 235.341 da comarca de Mairiporã, publicado em $O$ Estado de S. Paulo de 25 de janeiro de 1976, julgando procedente o pedido de retificação de sexo no registro de nascimento, por se tratar, sem sombra de dúvida, de caso de hermafroditismo.

Por outro lado, no acórdão n. 247.425, de 25/12/75, da $5^{\text {a }}$ Câmara Cível do Tribunal de Justiça de São Paulo, decidiu-se que os órgãos genitais atrofiados do apelante não poderiam justificar a ablação efetuada, quiçá até criminosa, pois continuava o apelante a ser do sexo masculino, não possuindo os órgão sexuais internos femininos, como o útero e os ovários. Daí negar-se o tribunal a admitir a averbação de alteração de sexo no registro de nascimento pertinente.

\section{j. Outros registros ou documentos}

Nos EUA, os transexuais podem, como já foi mencionado, com relativa facilidade, obter mudança de nome através de determinação judicial e obter os documentos secundários como carteira de habilitação de motorista, carteira de Previdência Social, registro de batismo, passaportes e diplomas escolares.

\section{V - O Direito Social}

1. Pagamento de auxílios médicos e sociais

Outra área que afeta diretamente os transexuais é a questão de auxílios médicos e sociais, isto é, o direito a tais auxílios, como, por exemplo, pensão por incapacidade.

O Departamento de Saúde, Educação e Previdência dos Estados Unidos da América dispõe de serviços médicos com a finalidade de incentivar o emprego de indivíduos incapacitados, sendo todos esses serviços inúteis se não puder o transexual ser qualificado como incapacitado.

De fato, nem o "Diagnostic and Statistic Manual of Mental Disorders", nem o "Eighth Revision, International Classification of Diseases" colocou o transexualismo na categoria de doença mental ou fisica. A dra. Maria 
Mehl, da Fundação Erickson, afirmou que não existe teste físico ou psicológico suficientemente sensível para diferençar o transexual da assim chamada população normal.

Contudo, alguns Estados americanos, a fim de proporcionar aos transexuais ajuda previdenciária, incluem-nos na categoria de incapacidade psíquica. $^{82}$

Por outro lado, existem decisões que reconhecem direitos ao transexual, em virtude de sua condição particular, como, por exemplo, a que reconheceu, a um transexual, o direito de aposentar-se aos 62 anos, ao invés de 65 anos, como exigido pelas leis previdenciárias americanas. ${ }^{83}$

\section{Discriminação no trabalho}

A operação de redeterminação sexual cria para o transexual graves problemas no relacionamento social, entre os quais aqueles que dizem respeito ao trabalho. Não pode registrar-se para trabalhar nem como homem, nem como mulher, em razão de sua condição.

A dispensa do transexual pós-operado ofende o Título VII do "Civil Rights Act" (EUA) de 1964, que proíbe ao empregador discriminar quanto à raça, cor, religião, sexo ou nacionalidade do indivíduo? A dispensa de um transexual por entidade governamental significaria a negação de igualdade de tratamento perante a lei? Existem tipos de trabalhos peculiares aos transexuais? Poderia a determinação de inadequação ou incapacidade para certos trabalhos ser generalizada a fim de definir direitos em outras áreas? ${ }^{84}$

Todas essas questões poderiam ser formuladas no Brasil, face à nossa Constituição e à Consolidação das Leis do Trabalho. Senão vejamos:

Vamos encontrar em nossa Carta Magna, 1946, em seu art. 157, inciso II: "A proibição de diferença de salário para um mesmo trabalho por motivo de idade, sexo, nacionalidade ou estado civil" Esta mesma proibição é estabelecida no inciso III do art. 165 da Emenda Constitucional de 17/10/1969, encontrando-se, no inciso $\mathrm{X}$, proibição de trabalho em indústrias insalubres, para as mulheres; e o inciso

82. Legal Aspects of Transsexualism, Erickson Educational Foundation Publication.

83. New York supplement, 2d. series - 293 -355 - 347 - 314.

84. Federal Legislation Prohibiting Discrimination on the Basis of Affectional or Sexual Preference. By the Special Committee on sex and law, p. 363. 
XIX preceitua a aposentadoria para mulher aos 30 anos de trabalho, com salário integral.

Verificamos, ainda, que na Consolidação das Leis do Trabalho, em seu art. $5^{\circ}$, está estipulado que "a todo trabalho, de igual valor, corresponderá salário igual, sem distinção de sexo"

Encontramos, ainda, a confirmação da estipulação acima no art. 461: "sendo idêntica a função, a todo trabalho de igual valor, prestado ao mesmo empregador, na mesma localidade, corresponderá igual salário, sem distinção de sexo, nacionalidade ou idade"

Nos Estados Unidos, estas questões começaram a ser tratadas pela primeira vez na decisão do Tribunal de Apelação de New Jersey no caso "In Re Tenure Hearing of Grossman" 85

VI - O Direito Público

1. A lei penal

Sob este tópico, podemos fazer referência aos contatos sexuais, que serão ou poderão ser considerados homossexuais, embora subjetivamente o transexual os considere heterossexuais. O problema penal existiria, obviamente, nas legislações que considerassem o homossexualismo como crime.

Outro aspecto de interesse na esfera criminal é o problema de apresentar-se o transexual com roupas do sexo oposto. Referimo-nos especialmente

85. Paula Grossman, transexual que se transformou em mulher (anteriormente Paul Grossman), mantinha, por muitos anos, a posição de professor de música na escola primária de Bernards Township. Após a mudança de sexo, foi suspensa, sem pagamento, pela Secretaria de Educação. A decisão do tribunal foi pela inadequação de tal pessoa para a profissão do ensino, não quanto aos seus conhecimentos sobre a matéria, mas em razão da influência psicológica sobre as crianças, que tinham conhecimento de sua mudança de sexo, o que, para a hipótese, constituiu-se em uma incapacidade. $\mathrm{O}$ tribunal, contudo, circunscreveu essa incapacidade somente para aquela escola, naquele lugar particular. Mas a esperança de ensinar em outros lugares seria ilusória, pois Paula Grossman não podia esconder a mudança de sexo em seus documentos oficiais. O tribunal outorgou-lhe o pagamento atrasado e o direito de pedir uma pensão por incapacidade. Como, porém, fazer valer esse direito se ela não apresentava nenhuma incapacidade mental ou fisica? O tribunal, porém, não aceitou a alegação de discriminação quanto ao sexo nem o argumento relativo à igualdade de proteção, afirmando que os direitos e necessidades dos menores opor-se-iam terminantemente aos do transexual.

The Law and Transsexualism, Connecticut Law Review, v. 7:288. 
ao transexual masculino para feminino e, também, às legislações onde tal prática seja criminosa. ${ }^{86}$

Grande parte das clínicas que oferecem tratamento ao transexual recomenda que ele se vista com as roupas do sexo oposto e que viva de acordo com esse sexo durante, mais ou menos, dois anos antes da cirurgia. Esta medida serve como diagnóstico, provando a sinceridade do transexual e facilitando o seu ajustamento social após a cirurgia. ${ }^{87}$

Atualmente tanto nos Estados Unidos quanto na Inglaterra, a lei considera que toda a atividade sexual privada, quer entre heterossexuais, quer entre homossexuais, entre adultos que livremente consentem, não envolvendo corrupção de menores, não ofende a lei criminal. Em outras palavras, estão excluídas da esfera da lei penal todas as práticas sexuais privadas que não envolvam coação, corrupção de menores ou ofensa ao pudor público. ${ }^{88}$

É esta também a situação perante a lei penal brasileira, no que respeita à liberdade sexual do transexual, sem querermos, neste passo, entrar em consideração sobre os crimes que possam, eventualmente, ser praticados contra os transexuais.

86. Nos Estados Unidos, para evitar que o transexual, durante o período pré-operatório, quando vestir roupas do sexo oposto, seja detido pela polícia, é necessário que tenha consigo uma declaração do médico sob cujos cuidados se encontra, redigida nos seguintes termos:

"A quem possa interessar:

Esta certifica que João de Tal, residente....., está sob tratamento de condição neuroendocrinológica, conhecida como transexualismo. Está autorizado a viver e vestir-se como mulher, usando o nome de Joana de tal, durante a fase pré-operatória do tratamento. O Sr. ou Sra. de Tal não tem inclinações criminosas e o seu transvestismo não tem o propósito de fraudar ou causar dano a qualquer individuo" Publication.

An Outline of Medical Managment of the Transsexual, Erickson Educational Foundation

Gutheil, E. A., The Psychologic Background of Transsexualism and Transvestism Am. J. Psychoter, 8, 231, 1954 ( notas bibliográficas ).

Hirschfeld, H., Sexual Pathologie, Marcus - Weber, Bonn (1918) (notas bibliográficas). bibliográficas ).

Lukianovicz, N., Transvestism and Psychosis Psychiat. Neurol., 138, 64, 1959 (notas

87. Lukianovicz, N., Survey of Various Aspects of Transvestism in the Light of our Present Knowledge - J. Nerv. Ment. Dis., 128, 36, 1959 (notas bibliograficas).

88. The Connecticut Law Review, 1975.

The Weekly Law Reports, p. 1.306, 1970.

Randel, J. B., Transvestitism and Trassexualism, Brit. Med. J. 2:1448, 1959 (notas bibliograficas). 
Em outras áreas do Direito Penal (e aqui nos referimos expressamente ao Título VII da parte especial do Código Penal Dos Crimes contra a Família) poderá o transexual praticar atos que o tornem incurso nos crimes definidos pelos arts. 236 e 237, do mesmo Código.

Se não quisemos abordar os crimes que, porventura, possam ou pudessem ser cometidos contra o transexual na área dos crimes contra os costumes, uma vez que o tratamento dessa questão envolveria a própria discussão do sexo do transexual, após a cirurgia de conversão, não hesitamos em fazer referência aos crimes cometidos contra o transexual na esfera das lesões corporais (Título I da parte especial do Código Penal Dos Crimes contra a Pessoa).

O dr. Paul M. Packman, professor de Psiquiatria da Universidade de Washington, EUA, afirma: "não há dificuldades legais e a operação cirúrgica nos transexuais não é considerada com causadora de graves lesões corporais" ${ }^{89}$

Contudo, embora não exista lei que, especificamente, proíba a cirurgia de redeterminação sexual, nenhum membro do Ministério Público nos EUA, deixa de informar ao médico ser tal operação ilegal e enquadrada pelo "Mayhem Statute" 90

Destaca-se que, seja qual for o fundamento da licitude do tratamento médico-cirúrgico (estado de necessidade; consentimento do interessado, exercício de um direito profissional, autorização legal, interesse social, costume, etc.), a conclusão emergente coincidirá no essencial, ou seja, a ilicitude da atuação médicocirúrgica.

Poderia parecer, à primeira vista, num exame menos profundo, que, no caso da cirurgia de conversão, fosse suficiente o consentimento do paciente para legitimar o exercício regular de uma faculdade do médico.

Mas, abordando a questão do consentimento do titular do bem, devemos lembrar que esta questão não é pacífica como causa da exclusão do ilícito. Muito se tem discutido quanto aos direitos sobre a própria pessoa e, conseqüentemente, se existe um direito subjetivo sobre o próprio corpo, que possa ser concebido como um direito de propriedade ou simplesmente um direito pessoal de disposição nos limites impostos pela lei.

89. Declaraçðes juntadas aos autos do processo $20 / 76$ da $17^{\circ}$ Vara Criminal do TJSP.

90. Block, Norman L.; e Tessler, Arthur N., Transsexualism and Surgical Procedures. Reprint Medical Aspects of Human Sexuality, 1973. 
Asseguram alguns autores que esta questão foi sanada pelo Novo Código Civil italiano que, em seu art. $5^{\circ}$, preceitua: "os atos de disposição do próprio corpo são proibidos quando causem uma diminuição permanente da integridade fisica ou quando sejam por outro modo contrários à lei, à ordem pública e aos bons costumes" Essa norma se refere àqueles atos de disposição que se concretizam no "consentimento do titular do direito" mas esse consentimento não pode ser contrário à lei, à ordem pública e aos bons costumes.

Examinando o preceito acima, Adriano de Cupis ${ }^{91}$ nos ensina que é de interesse público a tutela à integridade física dos indivíduos, na medida em que tal integridade constitui condição de vivência normal, de segurança, de eficaz desenvolvimento da atividade individual proficua.

$\mathrm{O}$ direito à vida e à integridade corporal é irrenunciável e não suscetível de disposição, razão pela qual Emilio Ondei $^{92}$ confirma a invalidade absoluta do negócio jurídico, gratuito, oneroso, bilateral ou unilateral, que atribui a terceiro um poder jurídico, quando contrário à lei, à ordem pública ou ao bom costume. Os autores italianos, assim, consideram que, quando as lesões corporais são contrárias ao estipulado no art. $5^{\circ}$ do C.C. italiano, o interesse público não pode consentir que o exercício do direito de punir do Estado dependa de um ato de vontade particular.

Fazemos referência a "L'Indice Penale", o qual não trata da matéria, pelo menos durante maio a agosto do ano de $1973 .{ }^{93}$

Foi decidido por tribunais argentinos que "para excluir $a$ antijuridicidade de uma operação cirúrgica de mutilação ou incapacidade fisica ou psíquica não é válida a autorização do paciente" 94

Portanto, ninguém pode autorizar que o mutilem ou o incapacitem fisica ou psiquicamente, já que a tutela penal não implica aqui em um simples direito subjetivo, mas em um interesse social e público; o lesado, cuja integridade psicofísica é o objeto material da ação, carece da faculdade de decidir sobre o objeto da proteção que pertence igualmente à sociedade, resultando imputável, ainda que a

91. Cupis, Adriano de. Os Direitos da Personalidade. Morais Editora Lisboa, p. 69, 1961.

92. Ondei, Emilio, Le Personne Fisiche e i Diritti della Personalità (notas bibliográficas).

93. L'Indice Penale, Edizioni Cedam, Padova, anno VII - n. 2 - maggio-agosto, 1973.

94. Jurisprudência Argentina.. Série contemporânea, 1970. 
lesão seja consentida, porquanto a integridade corporal do indivíduo é um bem indisponível.

José Severo Caballero, doutrinador argentino, inspirando-se na doutrina italiana a respeito do direito de exercício da profissão médica, afirma "se não for contrário ao direito como unidade, pois a proteção da integridade fisica das pessoas é de ordem pública, sem subordinar-se à vontade individual, salvo exceções expressas, porque são nulos os atos de disposição de partes do próprio corpo por carecer de objeto a ser contrário à moral e à ordem pública.'

Para José Castan Tobeñas o próprio corpo é uma das coisas que não está no comércio dos homens (extra commercium) e, portanto, está excluído dos contratos.

A lei argentina n. 17.132, de 24/01/67, ao estabelecer as obrigações dos profissionais em Medicina, estatui, em seu art. 19, inciso 4: "não praticar intervenções cirúrgicas que modifiquem o sexo do paciente, salvo autorização judicial"

Pergunta-se: o médico que efetuou cirurgia em transexual poderia obter absolvição alegando falta de dolo? O doutrinador argentino Roberto A. M. Teran Lomas esclarece que "o único meio para se chegar à absolvição, no âmbito da culpa, seria a invocação de um erro essencial, fundado na confusão entre um homossexual e um intersexual" 95

Continuando a dissertar sobre a questão do consentimento, o doutrinador espanhol Cuello Calón, comentando o Código Penal espanhol, argumenta que "a legitimidade do exercício profissional não se refere à atuação dentro de certos limites, mas principalmente ao exercício da profissão com um fim legítimo: assim o médico que pratica uma intervenção cirúrgica para salvar a vida de um enfermo, age legitimamente, pois a salvação de uma vida é um fim legítimo, mas quem esteriliza ou procede a ablação do sexo de uma pessoa, mesmo com o seu consentimento, comete um fato delituoso, porque sua atuação é ilegítima"

No Brasil, os doutrinadores Nelson Hungria e Aníbal Bruno são concordes quando ensinam não valer o consentimento, quando o bem jurídico tem por titular o Estado, ou representa um valor coletivo, ou a sua proteção transcende 
do domínio exclusivo do interesse privado, sendo a vontade de seu titular insuficiente para decidir da sua disposição. ${ }^{96}$

O Código Civil brasileiro, no seu art. 1.545, previu a responsabilidade civil do médico, exigindo que esse profissional exerça sua arte segundo os preceitos estabelecidos e com as cautelas e precauções necessárias ao resguardo da vida e da saúde dos clientes, bens inestimáveis que a ele são confiados com o presśuposto de zelar por eles. ${ }^{97}$

No caso do transexual, levando em consideração tudo o mais que acima foi exposto, verificamos que não pode validamente dispor do direito lesado, ou seja, do direito à sua integridade física, e, por sua vez, o cirurgião que se propusesse a efetuar a operação de conversão, valendo-se do consentimento vedado do transexual, não conseguiria afastar de si a responsabilidade criminal, pois que caracterizada estaria a antijuridicidade do ato.

\section{A Lei Magna}

A Lei Magna se propõe a assegurar a liberdade individual no campo da política, da moral, da religião, do trabalho, da propriedade, da intimidade do lar e, acima de tudo, a vida. E isto o faz em razão de princípios basilares aceitos universalmente. Não estipula especificamente sobre a liberdade do homem de dispor de seu próprio corpo. Mas infere-se que, sendo a incolumidade do corpo de cada indivíduo de suma importância para ele próprio, a merecer tutela especial do Estado, não tem o indivíduo, dentro do atual ordenamento jurídico, a liberdade de dispor do próprio corpo.

Tecendo comentários à Lei Magna de 1967 em seu art. 153, Pontes de Miranda faz referências ao conceito de liberdade, dizendo que esta existe para o indivíduo, mas, quando este é lesado por ela, o Estado vem em sua proteção, para ampará-lo. Donde se pode inferir, mais uma vez, que não é dada ao indivíduo a liberdade de dispor do próprio corpo. ${ }^{98}$ 128.

96. Hungria, Nelson, Comentários ao Código Penal, v. V., Revista Forense, Rio de Janeiro, p Bruno, Aníbal, Direito Penal - Parte Geral, tomo 2, p. 17.

97. Machado, Paulo Affonso Leme, A Responsabilidade Médica Perante a Justiça, R.T. 494/245.

98. Miranda, Pontes de, Comentários à Constituição de 1967 com a Emenda n. I, de 1969, tomo IV, p. 617. 
VII - Conclusð̃es

A leitura deste trabalho deixa claro que a área do transexualismo, sob o aspecto legal, é caótica e contraditória, e, como tal, se apresentam as decisões dos tribunais americanos em questões trazidas à sua apreciação, gerando inúmeras dúvidas, mais do que esclarecendo-as ou dando-lhes soluções.

Os nossos tribunais, como já mencionamos, não admitem a averbação da mudança do sexo e do nome no caso dos transexuais e voltam-se contra o médico que haja praticado essas operações de conversão sexual, enquadrando-o no art. 129 do Código Penal.

O transexualismo apresenta-se como verdadeiro desafio ao sistema legal.

Os estudiosos da questão já disseram que não é a lei que decidirá sobre o sexo do indivíduo, mas que o sistema legal deve seguir os pronunciamentos da Medicina, que deveria ser o seu instrumento.

O que se verifica, porém, é que o conteúdo médico do problema do transexualismo diminui à medida que predomina o conteúdo legal, visto que a determinação do sexo para efeito do registro de nascimento, status marital, status de parentesco, etc. são problemas essencialmente legais. Pode-se dizer que a Lei não deve se opor ao julgamento médico quanto ao diagnóstico e ao tratamento, mas a Medicina não pode decidir quanto ao posicionamento do transexual em face dos vários contextos legais.

E o que se verifica, ainda, é que o transexualismo não tem, por parte do sistema legal, a aceitação que se poderia esperar à vista da substancial literatura sobre o problema. Uma das maiores formas de oposição a tal aceitação advém do temor de que as facilidades legais para a mudança de sexo possam engendrar operações para a satisfação de caprichos momentâneos. Proclama-se ainda que é diminuto o número de indivíduos nos quais o problema se manifesta.

Isto nos leva a crer que a cirurgia não deva ser adotada como solução do problema do transexualismo, especialmente porque, como já mencionamos em outra parte deste trabalho, ela não transforma realmente uma pessoa de um sexo em uma pessoa do outro sexo, nem mesmo externamente, pois a técnica cirúrgica, por mais aprimorada que seja, nem de longe consegue reproduzir os órgãos naturais do indivíduo. Tampouco consegue a cirurgia, atualmente, realizar transplantes de 
órgãos sexuais internos, razão por que, da operação, resultam sempre indivíduos estéreis.

Não queremos afirmar que a esterilidade, por si só, possa erigir-se em argumento decisivo contrário à cirurgia de conversão, e, embora não podendo negála como consequiência necessária dessa cirurgia, afigura-se-nos como mais um argumento a demonstrar a imperfeição dessa solução.

Outro argumento seria o transexualismo tratar-se de uma doença de personalidade, não sendo passível de erradicação por meio da cirurgia.

Seria de supor que, muito cedo, iria o transexual pós-operado convencer-se da inutilidade de seu gesto para consecução de seus objetivos, não-só pela impossibilidade de levar uma vida normal, como ainda pelas dificuldades pessoais de toda ordem, que, fatalmente, iria enfrentar por toda a sua vida, sendo sempre objeto de espanto, curiosidade, escárnio, desprezo, asco e de outros mais sentimentos de que seja capaz a alma humana. Cremos que a sua angústia aumentará em face da irreversibilidade da situação. E poderá tornar-se muito mais infeliz que antes da cirurgia.

Não negamos que, ao transexual, devam ser dadas condições para a adaptação ao meio social. Achamos, simplesmente, que a cirurgia não é o meio de consegui-lo. Preferimos optar por uma regulamentação de tratamento que deveria ser proporcionado ao transexual em clínicas especializadas.

$O$ fato de não existir ainda tratamento efetivo para o transexualismo não nos parece seja argumento definitivo para que se adote a cirurgia como solução de seu problema, visto que, como procuramos mostrar, ela não o é.

Ao contrário, parece-nos que deve a Psicanálise intensificar suas pesquisas, talvez alterar seus métodos, para buscar na mente a solução de um problema mental, muito embora se afirme que os transexuais são indivíduos psicologicamente sãos, isto é, não evidenciam psicoses, esquizofrenia ou outras doenças mentais sérias. Essa afirmação, todavia, parece refletir menos uma verdade do que um atraso no conhecimento das manifestações psíquicas do indivíduo e da maneira de apreciá-las ou corrigi-las.

A cirurgia de conversão, portanto, deveria ser explicitamente proibida. Não se pense que esta opinião tem puramente a finalidade de resolver problemas legais, da mais variada ordem, de maneira simplista. Ao contrário, vemos na proibição uma proteção ao indivíduo, uma tentativa de impedir seu sofrimento após 
a cirurgia, uma tentativa de impedir sua ação talvez precipitada e impensada e irreversível.

Pelas mesmas razões, e, como maneira efetiva de impedir a prática de tal cirurgia, deveria o Código Penal definir como crime a automutilação, sem relevante razão de direito, bem como a submissão voluntária à cirurgia que trouxesse consigo aquela conseqüência.

Embora compreendamos que em outros países esta questão já ultrapassou o campo experimental e que existe um hiato entre as normas jurídicas e o estágio médico atual, consideramos que cabe ao legislador elaborar leis que regulem esta situação.

Tendo pesquisado, examinado e refletido a respeito dos fatos aqui expostos, tivemos a preocupação de, na medida das nossas possibilidades, apresentar uma contribuição ao estudo de um problema que, aos poucos, se avoluma.

Não temos a veleidade de ter alcançado todos as aspectos do complexo problema, pois sabemos das nossas limitações, num trabalho isolado, mas esperamos ter fixado uma posição que possa servir para intensificar o interesse neste campo do comportamento humano.

Este trabalho não teria sido elaborado sem a contribuição proficua dos queridos mestres professor Washington de Barros Monteiro e professor João Baptista de Oliveira e Costa Júnior, dos meus prezados colegas dr. Sérgio Marcos de Moraes Pitombo e dr. Cândido Rangel Dinamarco e, mais, do dr. Leonardo Frankental e do dr. Arnaldo C. Sandoval, que enriqueceram minhas fontes de pesquisa, colocando, à minha disposição, selecionada bibliografia.

A todos eles, os meus mais profundos agradecimentos.

\section{BIBLIOGRAFIA}

Afirmações feitas em cartas juntadas ao processo criminal n. 20/76 da Vara Criminal.

Almeida Jr. Medicina Legal. Editora Nacional. Anglo American Law Review, 1973. An Outline of Medical Management of the Transsexual - Erickson Educational Foundation Publication. Arizona Reviewed statute annotated, 1976. 
Associação Paulista de Medicina. O Médico Paulista, public. da $1^{a}$ quinzena de dezembro de 1976.

Atlantic Reporter, 2 ed.

Benjamin, H. The Transsexual Phenomenon, New York: The Julian Press, 1966.

Benjamin, H. e Ihlenfeld, Charles L. - The nature and treatment of transsexualism, Reprint Medical Opinion of Review, v. 6, n. 11, 1970.

Transexualismo, American Journal of Nursing, v. 73, n. 3, 1973.

Block, Norman L.; e Tessler, Artur, N. Transexualismo and surgical procedures Reprint Medical Aspects of Human Sexuality, 1973.

Brent, Gail - Some Legal Problems of the Post Operative Transsexual - Journal of Family Law, v. 12, 1972-1973.

Bruno, Aníbal - Direito Penal - Parte Geral Tomo 2 - p. 17.

Canadian Medical Association Journal - 1970.

Change of sex on Birth certificates for transsexuals - Bulletin of New York Academy of Medicine - v. 42 - n. 8, 1966.

Código de Ética Médica.

Coelho, Vicente de Faria Nulidade e Anulação do Casamento - Freitas Bastos, p. 27.

Cunnan and Shapiro - Law, Medicine and Forensis Science p. 836 - 2 ed., 1970.

Cupis, Adriano de - Os direitos da personalidade - Lisboa, 1961.

Declarações juntadas aos autos do processo 20/76 da $17^{\mathrm{a}}$ Vara Criminal do TJSP.

Dinamarco, Candido Rangel, Razões da Apelação do Dr. Curador do R.P. Processo n. 1.118/70, acórdão public. RT 444 .

Drake, Donald C. - Crossing the sex Barrier - Science Revue World, 1974.

Epps Dorina Rossetta G. Depoimento constante de processo criminal n. 20/76 da $17^{\mathrm{a}}$ Vara Criminal de S. Paulo.

Ética Médica e Lei Penal - O Estado de S. Paulo, em 12.03.1976.

Fávero, Flamínio - Medicina Legal - Martins Editora - $2^{\circ}$ v., p. 187.

Federal Legislation Prohibiting Discrimination on the Basis of affectional or sexual preference. By the Special Committee on sex and law - p. 363.

França, Rubens Limongi - Do Nome Civil das Pessoas Naturais Rev. dos Tribunais - p. 193.

Guidelines for Transsexuals - Erickson Educational Foundation Publication.

Hamilton William e Walker, David W. Gender - Quaestio Ovid Juris? Médicine, Science and Law, 1975. 
Holloway, John P Transsexuals and their "legal sex" - Johns Hopkins Press Baltimore, 1969.

Hungria, Nelson - Comentários ao Código Penal, v. V Revista Forense - Rio de Janeiro - p. 128.

Ihlenfeld, Charles L. When a woman becomes a man - Sexology Magazine - 1972.

Instituto Médico Legal de São Paulo - Laudo de exame de corpo de delito juntado a processo criminal n. 20/76 - $17^{\mathrm{a}}$ Vara Criminal de São Paulo.

James, Thomas E. PHD - Legal issues of transsexualisn in England.

Jurisprudência Argentina - Série contemporânea, 1970.

Kannedy, Ian Mc Coll - Transsexualism and single sex mariage - Anglo American Law Review, 1973.

Kouri. Robert P. Comments on transsexualisn in the Province of Quebec - Revue de Droit Civil - Université de Sherbrooke Province of Quebec, 1973.

Legal aspects of transsexualism Erickson Education Foundation Publication.

L'Indice Penale - Edizioni Cedam - Padova, 1973.

Lopes, Serpa - Curso de Direito Civil v. I, p. 327.

Machado, Paulo Afonso Leme - A responsabilidade médica perante a Justiça, RT 494/245.

Meyers, David William Problems of set determination and alteration, Médico Legal Journal, v. 36, p. 174, 1968.

Miranda. Pontes de, Comentários à Constituição de 1967 com a emenda n. 1 de 1969 - Tomo IV.

Money, J. e Green, R. Transsexualism and sex reassignment - Johns Hopkins Univ. Press, Baltimore, 1968.

Moore, Keith L., Intersexuality, Canadian Medical Ass. Journal, 1960.

New York Supplement - N.Y.S. 2d.

O Médico Paulista, Ass. Paulista de Medicina, n. 169.

Overzier, Claus - La Intersexualidad, Editorial Científico - Médica, Madrid, 1963.

Paiva, Luiz Miller de, Medicina Psicossomática, p. 69, 1966. Pauly, I. B. Adult manifestations of male transsexualism. Transexualism and sex reassignment Richard Green and John Money, Johns Hopkins Press, Baltimore, 1969.

Revista de Terapêutica Médica - Ars Curandi n. 2, 1968.

Rodrigues Armando Canger Aspectos Éticos do Transexualismo Trabalho apresentado no XI Congresso Brasileiro de Cirurgia Plástica - BH, 1974. 
. Transexualismo, transvestismo, homossexualismo e fetichismo Trabalho apresentado no X Congresso Brasileiro de Medicina Legal - São Paulo 1974.

Saldanha, P H.; e Olazabal, Luiza Campos Valor ' estudo citogenético no transexualismo Trabalho apresentado ao Simpósio patrocinado pelo Depto. de Urologia da Ass. Paulista de Medicina, 1975.

Salgado, Murilo Rezende - $O$ transexual e a cirurgia para a pretendida mudança de sexo -, RT 491/241.

Sarnoff, A. Mednick, do Psykologisk Institut K. benhavn, Denmark.

Sherwin, Robert Veit Legal Aspects of male transsexualism Johns Hopkins Press, Baltimore, 1969.

Solomon, Philip; e Patch, Vernon D. Handbook of Psychiatry - Lange Medical Publication, 1969.

Sturup, Georg K. Legal problems related to transsexualism and sex reassignment in Denmark - Johns Hopkins Press - Baltimore, 1969.

The Family Law Reporter - The Bureau of national affairs, Inc., 1975.

The Law and transsexualism - Connecticut Law Review, 1975.

The Weekly Law Reports New York, 1970.

Tove, Harold M. M. Clínicas Obstétricas y Ginecológicas Nueva Editoral Interamericana, 1973.

Transsexualism Médico Legal, 1968.

Transsexuals in Limbo, Maryland Law Riview, 1971.

Transsexualism sex reassignment surgery and the Law Cornell Law Review, 1971.

U.S. Supreme Court Proceedings The Family Law Reporter, v. n. 17, 1975.

Walinder, Jan - Medico Legal Aspects of Transsexualism in Sweden Johns Hopkins Press - Baltimore, p. 461, 1969.

Walinder, J.T. - A law concerning sex reassignment of transsexuals in Sweden 1976.

Walton, Terrence - When is a woman not a woman? New Law Journal, 1974.

\section{NOTAS BIBLIOGRÁFICAS}

Bekendtgreese om sterilisation of kastration - Justits Ministeriets, 1976.

Ehrhart, A. A. Transsexualism and cirurgical procedures. 
Gutheil, E. A. The psychologic background of transsexualism and transvestism Am. J. Psychoter., 1954.

Hirschfeld, M. - Sexual anomalies and perversions (London: F alder, 1936).

Krafft-Ebind, R. Psychopathia Sexualis, Milano, 1953.

Lukianovicz, N. - Survey of various aspects of transvestism in the light of our present knowledge - J. New Ment. Dis., 1959.

Lukianovicz, N. Transvestism and psychosis - Psychiat. Neurol., 1959.

Ondei Emilio - Le personne fisiche e i diritti della personalità.

Randel, J. B. Transvestitism and transexualism - Brit. Med J., 1959.

Sadi, Afiz - Urologia, 1975. 